04

\title{
Кварцевое стекло, полученное на плазмотронах ОАО „Динур“ из раменского песка: особенности кристаллизации на полированной поверхности
}

\author{
(С) А.Ю. Колобов ${ }^{1}$, Г.А. Сычева ${ }^{2}$ \\ ${ }^{1}$ ОАО ,ДИНУР“, \\ Первоуральск, Свердловская обл., Россия \\ ${ }^{2}$ Институт химии силикатов им. И.В. Гребенщикова РАН, \\ Санкт-Петербург, Россия \\ E-mail: art.kolobov@yandex.ru \\ Поступила в Редакцию 16 июля 2019 г. \\ В окончательной редакции 16 июля 2019 г. \\ Принята к публикации 25 июля 2019 г.
}

\begin{abstract}
Сырьем для плавки кварцевого стекла на ОАО „ДИНУР“ является кварцевый песок производства Раменского горно-обогатительного комбината (ГОК). От качества песков (содержания примесных компонентов, таких как оксиды алюминия и железа) существенно зависит производительность реакторов (плазмотронов) и качество получаемых слитков. Установлено, что продукт плавки кварцевого песка из исходного сырья с повышенным содержанием примесей отличается пониженной устойчивостью к кристаллизации.
\end{abstract}

Ключевые слова: Кварцевое стекло. Содержание примесей. Особенности кристаллизации. Устойчивость к кристобалитизации.

DOI: 10.21883/FTT.2019.12.48552.26ks

\section{1. Введение}

Свойства исходного сырьевого материала являются определяющими характеристиками физико-химических процессов, происходящих при плавке кварцевого стекла. В конечном итоге от них зависят свойства синтезированного стекла. Устойчивость кварцевого стекла к кристаллизации является одной из важнейших характеристик этого материала, определяет возможности и условия применения изделий из него при высоких температурах. Как правило, кристаллизация происходит на технологических включениях и дефектах стекломассы. На кристаллизацию кварцевого стекла сильное влияние оказывают различные примеси [1]. Отдельно в литературе рассматривается кристаллизация на газовых пузырьках. В настоящей работе исследовались особенности кристаллизации кварцевого стекла, полученного на плазмотронах ОАО, „Динур“ из кварцевого песка Раменского месторождения.

\section{2. Методы исследования и аппаратура}

Рентгенофазовый анализ (РФА) выполняли на установке ДРОН-7. Кривые нагревания кварцевых стекол получали на высокотемпературном дилатометре DIL-402 фирмы Netzsch. Оптическая микроскопия в отраженном свете выполнялась на микроскопе Neophot 32, в проходящем - на микроскопе Jenaval (оба производства фирмы Carl Zeiss, Jena, Германия).

\section{3. Экспериментальная часть}

\section{1. Характеристика исходного сырья}

Для синтеза кварцевых стекол в качестве исходных сырьевых материалов используют природный и синтетический кварц [2], кристобалит, аморфный $\mathrm{SiO}_{2}$, летучие соединения кремния: $\mathrm{SiCl}_{4}, \mathrm{Si}\left(\mathrm{OC}_{2} \mathrm{H}_{5}\right)_{4}$ и др. [3]. На ОАО „ДИНУР“ в качестве сырья для производства кварцевого стекла используют кварцевый песок месторождения „Раменское“, обогащенный и очищенный на Раменском горно-обогатительном комбинате (ГОК).

На рис. 1 приведен внешний вид кварцевого песка Раменского ГОК.

В центральной заводской лаборатории ОАО „ДИНУР“ проводят химический анализ получаемого из ГОК сырья. В таблице приведен результат химического анализа

Химический состав кварцевого песка, масс.\%, по анализу

\begin{tabular}{c|c|c|c|c|c|c}
\hline № пробы & $\mathrm{Fe}_{2} \mathrm{O}_{3}$ & $\mathrm{TiO}_{2}$ & $\mathrm{CaO}$ & $\mathrm{Al}_{2} \mathrm{O}_{3}$ & $\mathrm{SiO}_{2}$ & $\mathrm{Al}_{2} \mathrm{O}_{3}+\mathrm{TiO}_{2}$ \\
\hline 1 & 0.03 & - & 0.01 & 0.26 & $\mathbf{9 9 . 2}$ & 0.26 \\
10 & 0.02 & - & 0.04 & 0.21 & $\mathbf{9 9 . 2}$ & 0.21 \\
20 & 0.03 & - & 0.02 & 0.23 & $\mathbf{9 9 . 2}$ & 0.23 \\
30 & 0.04 & - & 0.03 & 0.35 & $\mathbf{9 9 . 1}$ & 0.35 \\
40 & 0.08 & 0.02 & 0.05 & 0.64 & $\mathbf{9 8 . 7}$ & 0.66 \\
50 & 0.02 & 0.01 & 0.01 & 0.36 & $\mathbf{9 9 . 2}$ & 0.37 \\
60 & 0.05 & 0.02 & 0.03 & 0.27 & $\mathbf{9 9 . 2}$ & 0.29 \\
70 & 0.04 & 0.01 & 0.04 & 0.23 & $\mathbf{9 9 . 0}$ & 0.24 \\
80 & 0.02 & - & 0.02 & 0.34 & $\mathbf{9 9 . 2}$ & 0.34 \\
90 & 0.02 & - & 0.04 & 0.38 & $\mathbf{9 8 . 9}$ & 0.38
\end{tabular}




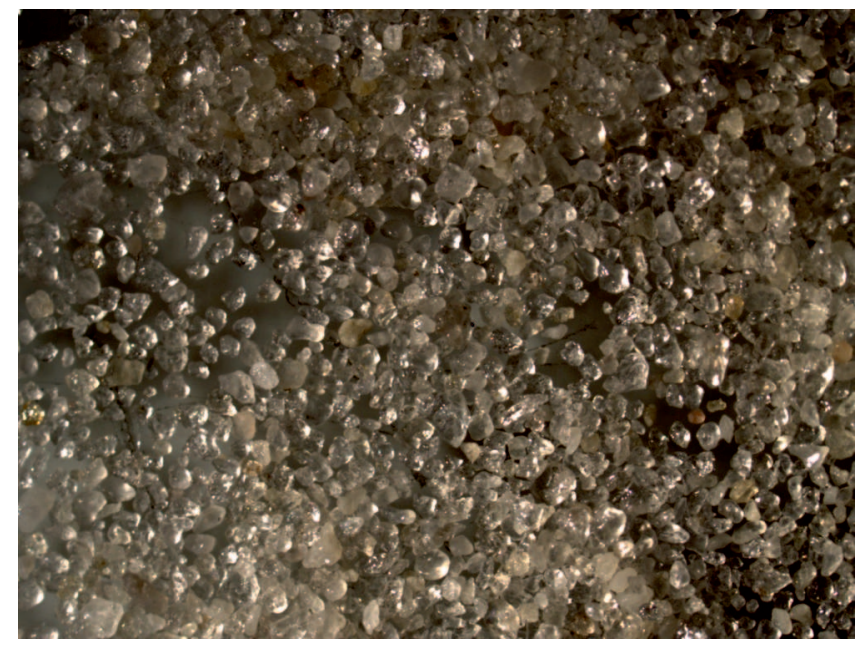

Рис. 1. Внешний вид исходного кварцевого песка Раменского ГОК.

кварцевого песка из различных его частей. Всего было взято 90 проб. В таблице представлены результаты каждой десятой пробы.

Как следует из рассмотрения данных химического анализа кварцевого песка месторождения Раменское, полученных из различных его участков, в основном на $99.2 \pm 0.2$ он состоит из $\mathrm{SiO}_{2}$, а в качестве примесей обнаружены оксиды железа, титана, кальция и алюминия.

\section{2. Плавка кварцевого песка}

Плавка кварцевого песка осуществляется в плазмотронах. Рабочий ток дуги реактора составляет 1300-1400 А при напряжении 300-400 V (точные характеристики зависят от качества песка - содержания примесей в песке оксидов алюминия и железа и составляют интеллектуальную собственность ОАО „ДИНУР“). Плавка кварцевого песка это самый первый этап в технологии производства изделий из кварцевого стекла. Кварцевый песок подается на дугу плазмотрона. Слиток в виде стержня (масса 600-680 kg) в процессе плавки находится в вертикальном положении. После плавки он вытягивается из камеры и помещается в зону охлаждения, где очищается от шубы, загрязнений, включений графитовых электродов. Затем очищенные слитки измельчаются сначала в щековой, а затем в роторной дробилках и сортируются по фракциям на (0-5) $\mathrm{mm}$ и свыше $5 \mathrm{~mm}$. Фракция более $5 \mathrm{~mm}$ возвращается на дополнительное дробление, а фракция (0-5) mm на виброситах рассевается на более мелкие фракции. Следующий этап - это подготовка литейного шликера кварцевого стекла, который идет на производство кварцевых изделий. Готовые изделия подвергают обжигу и сушке. Последняя стадия - сборка готовых изделий.

На рис. 2 представлены слитки кварцевого стекла, полученные в результате плавления кварцевого песка.
Слиток, полученный в результате плавления, представляет собой цилиндр длиной в несколько метров и около полуметра в диаметре. Внешняя корка слитка (т. н. „шуба“ $)$ представляет собой не проплавленную часть слитка, внутри которой находится готовый продукт плавки - кварцевое стекло. По данным химического анализа кварцевого стекла, содержание $\mathrm{Al}_{2} \mathrm{O}_{3}$ составляет 0,25\% и $\mathrm{Fe}_{2} \mathrm{O}_{3} \quad 0.05 \%$.

\section{3. Результаты рентгенофазового анализа кварцевого стекла}

На рис. 3 представлены рентгенограммы кварцевого стекла.

Рентгенограммы полученного продукта плавки имеют характерный вид аморфного образца - это широкая линия (гало) с угловой шириной $2 \theta$ около $20^{\circ}$. Для квар-

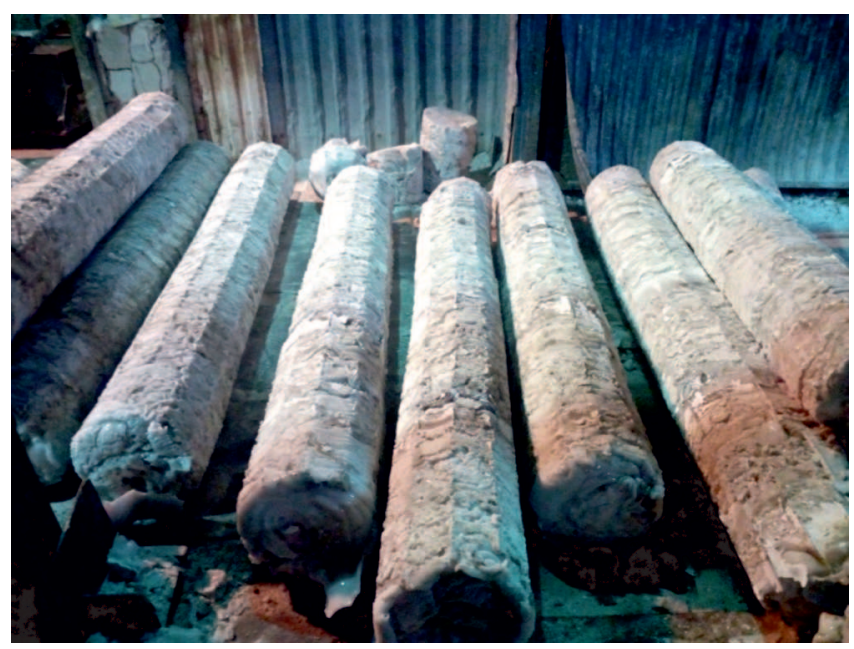

Рис. 2. Слитки кварцевого стекла, полученные в результате плавления кварцевого песка.

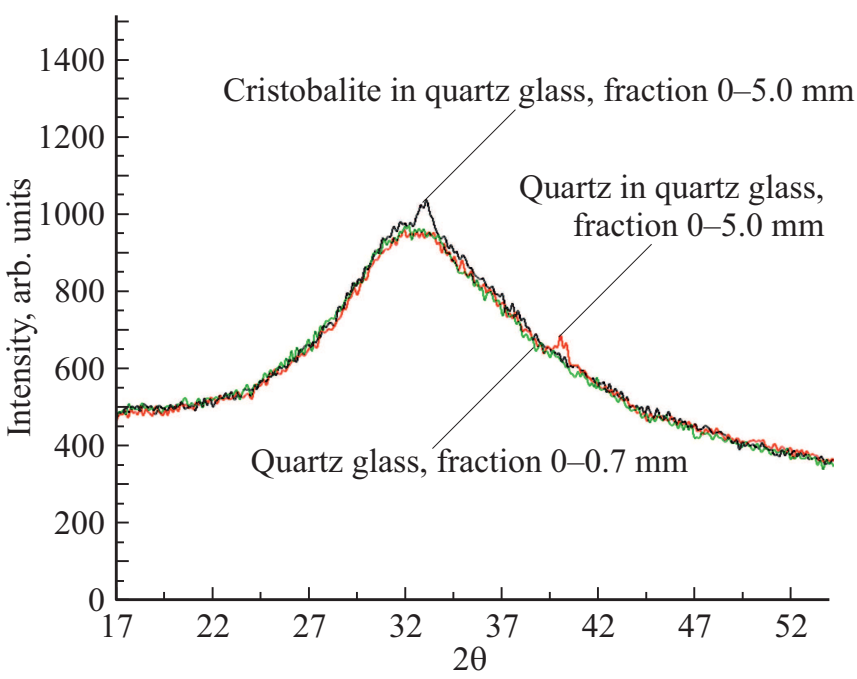

Рис. 3. Рентгенограммы кварцевого стекла различных фракций. 
цевого стекла характерно наличие ближнего порядка то есть наличие закономерности в расположении только для соседних атомов или молекул (1-10 $)$ ). А поскольку кварцевое стекло не имеет атомной решетки, то есть отсутствует периодичность в расположении атомов, то и нет четкой дифракционной картины и отдельных рентгеновских дифракционных отражений. Линия кварца на рентгенограмме может указывать на „непроплав“, а появление кристобалита объясняться особенностями режима плавки. При расчете содержания кристаллических фаз (кристобалит, кварц) по рентгеновским спектрам наиболее корректные значения могут быть получены при расчете интегральных интенсивностей максимумов в области с максимальным соотношением сигнал/шум. По данным рентгенофазового анализа, наибольшее количество кварца (10-12\%) было обнаружено в плотной корке на поверхности слитка, в то время как содержание кристобалита в корке не превышало $2 \%$. Минералогический состав большинства исследуемых образцов кварцевого стекла, очищенного от поверхностной кристаллической корки, представлен чистым силикатным стеклом. Кварц и кристобалит не были идентифицированы с помощью РФА в большинстве образцов. В тех образцах, где присутствие кристобалита было установлено методом РФА (в некоторых случаях до 1\%), петрографическое исследование подтвердило зарождение кристаллов на пузырьках газа, трещинах, вдоль свай или на границе инородных включений. В качестве таких включений могут выступать, например, частицы электродного графита или металла оборудования.

\section{4. Зависимости относительного изменения линейных размеров от температуры}

На высокотемпературном дилатометре DIL-402 фирмы Netzsch получены кривые нагревания кварцевых стекол (рис. 4).

Данные, аналогичные рис. 4 позволили оценить теплофизические характеристики для кварцевого стекла и изделий на его основе.

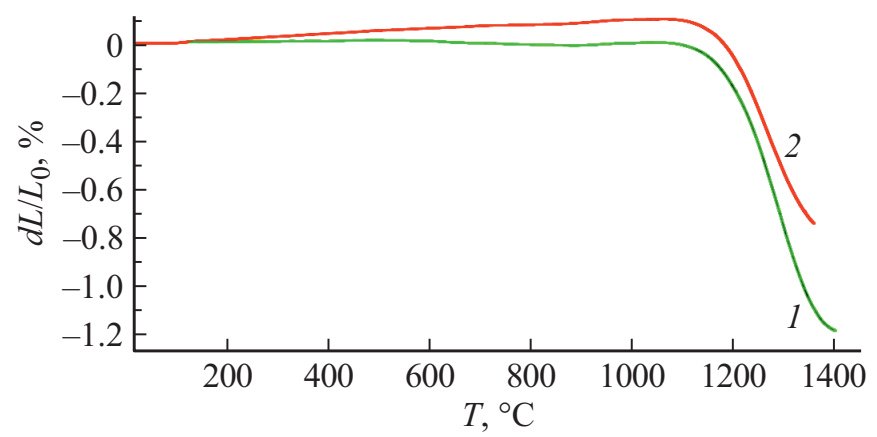

Рис. 4. Зависимости относительного изменения линейных размеров от температуры для кварцевых оболочек ОКСБ: 1 кривая первичного нагрева, 2 - кривая вторичного нагрева со скоростью нагрева $5^{\circ} / \mathrm{min}$.

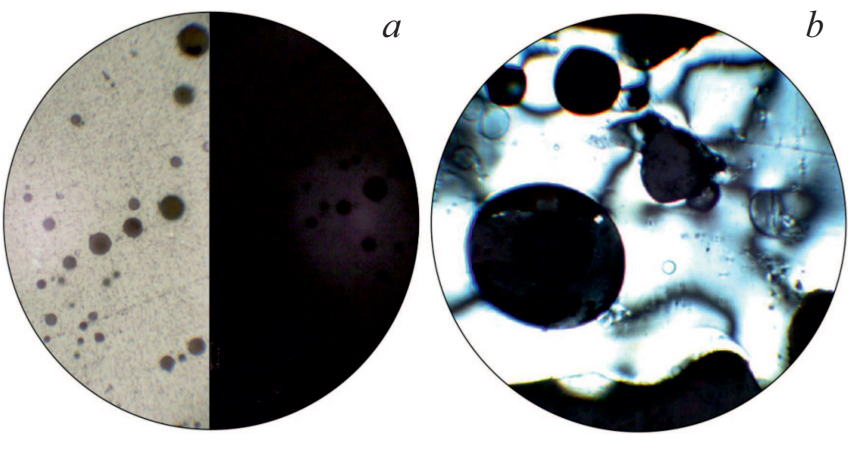

Рис. 5. Микроструктура центральной части $(a)$ и краевой части $(b)$ слитка кварцевого стекла. Условия съемки: $a-$ увеличение 50х в обычном (слева) и поляризованном (справа) свете, $b-$ увеличение $100 \mathrm{x}$, поляризованный свет.

\section{5. Зарождение кристаллов кристобалита в кварцевом стекле}

Стекло, как вещество с аморфной структурой, в поляризованном проходящем свете ведет себя аналогично оптически изотропным минералам. Однако, если в составе стекла имеются включения посторонних фаз, в частности кристобалита, это сразу диагностируется по аномальному угасанию. Из центральной и краевой частей слитка были вырезаны образцы стекла в форме пластинок, поверхности которых шлифовали и полировали. Затем образцы просматривали в оптическом микроскопе. В первом случае никаких отклонений в оптических свойствах вещества не наблюдалось. По всему объему, в том числе вокруг газовых пузырей, материал не просветлялся при включенном анализаторе (рис. 5,a). В краевых частях слитка („шубе“ ) (рис. 5, $b$ ) зафиксировали зоны с аномальным волнистым угасанием от сосредоточенных в местах скопления пустот от выхода газовой составляющей. Согласно данным РФА здесь отмечается наибольшее количество кристобалита.

По данным, аналогичным рис. 5, $a$ были определены размеры кристалликов кристобалита и построены распределения по размерам. При изотермической выдержке образцов кварцевого стекла наблюдаются два этапа процесса кристаллизации: индукционный период и рост кристаллического слоя. Индукционный период характеризуется отсутствием признаков появления кристаллов. Экспериментально длительность (величина) индукционного периода определяется следующим образом. Толщина кристаллического слоя сначала возрастает нелинейно со временем, а затем выходит на линейный участок роста. Тангенс угла наклона линейного участка зависимости дает значение стационарной скорости роста, $U_{\text {st. }}$ Пересечение продолжения линейного участка зависимости с осью времени определяет индукционное время зарождения $t_{\text {ind }}$. Это время, необходимое для достижения скоростью роста стационарного значения. Величины $t_{\text {ind }}$ и $\tau$ (время нестационарности) связаны соотношением $\tau=6 t_{\text {ind }} / \pi^{2}$. Для кварцевого стекла на 
начальной стадии роста слоя (до $10 \mu \mathrm{m}$ ) скорость роста слоя как правило меньше достигаемой позже стационарной скорости $U_{\text {st }}$ [4]. Для описания движения фазовой границы от поверхности в глубь стекла [5] для кварцевого стекла обычно пользуются моделью нормального роста [6].

\section{4. Обсуждение результатов}

Стеклообразный кремнезем начинает кристаллизоваться с поверхности. Образцы из кварцевого стекла в виде полированных пластин при температурах выше $1000^{\circ} \mathrm{C}$ еще стабильны. Коэффициент термического расширения (КТР) стекла и кристобалита при этих температурах близки и возникающие при этом напряжения быстро релаксируют. Частично закристаллизовавшийся образец стекла остается прозрачным и почти неотличимым от основного стекла. При этом кристаллизация повышает жесткость изделия из кварцевого стекла - закристаллизованные изделия могут использоваться вплоть до температуры плавления кристобалита. Установлено, что продукт плавки кварцевого песка из исходного сырья с повышенным содержанием примесей отличается пониженной устойчивостью к кристаллизации. Аналогичные результаты были получены в [7] и [8].

\section{5. Выводы}

Кварцевое стекло, полученное из исходного сырья кварцевый песок месторождения Раменское - отличается пониженной устойчивостью к кристаллизации. Основными кристаллическими фазами, обнаруженными в кварцевом стекле, синтезированном из данного сырья, являются кварц и кристобалит. В плотной корке на поверхности слитка (шубе) обнаружено от 10 до $12 \%$ кварца, содержание кристобалита в корке не превышало 2.0\%. Минералогический состав большинства исследуемых образцов кварцевого стекла, очищенного от поверхностной кристаллической корки, представлен чистым кварцевым стеклом. Кварц и кристобалит не были обнаружены с помощью РФА и микроскопии в большинстве образцов. В тех образцах, где присутствие кристобалита было установлено методом РФА, петрографическое исследование подтвердило зарождение кристаллов на посторонних примесях.

\section{Конфликт интересов}

Авторы заявляют, что у них нет конфликта интересов.

\section{Список литературы}

[1] W.A. Tiller, K.A. Jackson, J.W. Rutter, B. Chalmers. Acta Metallurg. 1, 428 (1953).

[2] В.П. Прянишников. Система кремнезема. Изд.-во лит. по строительству, Л. (1971). 238 с.
[3] W.H. Dambaugh, P. Schults. Vitreous silica. In: Encyclopedia of chemical technology. 2nd. ed. N.Y. (1969). V. 18. P. 73-102.

[4] В.К. Леко, Л.А. Комарова. Изв. АН СССР. Неорган. материалы. 7, 2240 (1971).

[5] D.R. Ulmann. Crystal growth in glass-forming systems - a review. In: Advances in nucleation and crystallization in glasses. Columbus. (1972). P. 91-115.

[6] N.G. Ainslie, C.R. Morelock, D. Turnbull. Devitrification kinetics of fused silica. In: Symposium on nucleation and crystallization in glasses and melts. Columbus. (1962). P. 97107.

[7] Ю.Е. Пивинский, П.В. Дякин, А.Ю. Колобов. Новые огнеупоры 1, 22 (2016).

[8] А.И. Непомнящих, А.А. Шалаев, Т.Ю. Сизова, А.Н. Сапожников, А.С. Паклин. География и природные ресурсы 6, 60 (2016).

Редактор Д.В. Жуманов 